\title{
Parameter Optimization of Friction Stir Welding For Aluminium Alloy
}

\author{
Arjun Verma ${ }^{1}$, Ankit Kumar Dubey ${ }^{2}$, Abhijeet Ganguly ${ }^{2}$ \\ ${ }^{I} M$ - Tech scholar, Department of Mechanical Engineering, GD Rungta college of Engineering \& Technology, \\ Bhilai (C.G.),India \\ ${ }^{2}$ Assistant Professor, Department of Mechanical Engineering, GD Rungta college of Engineering \& \\ Technology, Bhilai (C.G.), India
}

\begin{abstract}
In this paper, parameter of friction stir welding of marine grade aluminium alloy 5083 and high strength aluminium alloy 2024 T3 have to be predicted. The present work shows that different types of alloy materials have highest effect on mechanical properties of the specimens taken from welded zone. They were tested for mechanical properties such as tensile strength and Rockwell hardness respectively and are optimize with TOPSIS method to predict the parameter of welding joints.
\end{abstract}

Keywords: Friction Stir welding (FSW), Aluminium alloy, Tensile Strength, Rockwell Hardness.

\section{Introduction}

During the process, several changes occur in the mechanical properties and microstructure of the material due to plastic deformation. These changes in properties of material are affected by the welding conditions, such as rotational speed, feed rate and welding medium. Given the great potential of friction stir welding, this project is dedicated to find the relations between the changes in mechanical properties and microstructure and the weld parameters. The study aims at finding the optimum welding parameters to weld aluminium alloy 5083 with $2024 \mathrm{~T} 3$ developing a numerical model to further investigate the process. Friction Stir Welding is a solid state joining technique which is widely being used for aerospace, marine, automotive and other applications for joining similar and dissimilar metals. The friction stir welding (FSW) process offers the possibility for joining the metallic materials which are difficult of impossible to join by conventional welding techniques. Most of these materials are lightweight metals and their alloys, such as aluminium, which has good corrosion resistance, stiffness to mass ratio (ratio of elasticity modulus and density) and strength to weight ratio. Bearing in mind the increase of usage in civil engineering and transport industry, including shipbuilding and airplane industry, aluminium alloys and their joining procedures are gaining more and more attention [1].

When tool feeds towards the part of plates which are in front of tool leave fixture surface and scroll around tool and rupture occurred. For this problem one can use clamps closely together also a roll which moves infront of tool and prevents sheets to go upward can be used. Friction Stir Welding (FSW) is a hot - shear joining process in which a non-consumable rotating tool plunges into rigidly clamped work piece and moves along the joint to be welded [1]. FSW is carried out below the melting temperatures of the metals. The schematic diagram of the FSW is shown in the Figure 1.

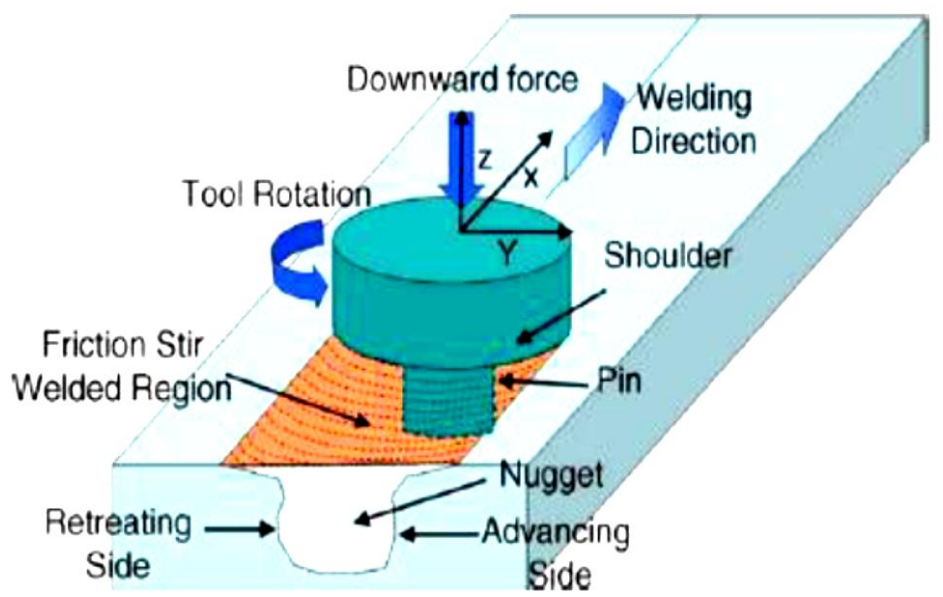

Figure 1 Schematic Drawing of Friction Stir Welding [3] 


\section{Review Work}

Cavaliere et al. (2006) studied mechanical and microstructural properties of dissimilar 2024 and 7075 aluminium sheets joined by friction stir welding[2]Cao and Kou further found that $\theta$ particles could reach sizes of $100 \mathrm{~m}$ during friction stir welding [7]. Duo Liu et al. (2011) investigated the microstructure and mechanical properties of friction stir weld joints of dissimilar Mg alloys AZ31 and AZ80. It was found that the material with inferior plastic deformability (AZ80) should be set at the advancing side and the material with superior deformability (AZ31) should be set at the retreating side to get sound FSW joint of dissimilar Mg alloys. [4]

Esther T Akinlabi et al. (2012) conducted statistical analysis on the weld data obtained from friction stir welding of aluminium and copper. The welds were produced by varying the process parameters; the rotational speed was varied between 600 to $1200 \mathrm{rpm}$ and the welding speed varied between 50 and 300 $\mathrm{mm} / \mathrm{min}$. It was found that the downward vertical force has a significant effect on the Ultimate Tensile Strength of the weld and a strong relationship exist between the heat input into the welds and the measured electrical resistivity of the welds.[5]

Firouzdor and Kou (2009) were investigated the effect of positions of $\mathrm{Al}$ and $\mathrm{Mg}$ with respect to the welding tool in friction stir welding of $\mathrm{Al}$ to $\mathrm{Mg}$. It was found that the heat input and joint strength can be significantly affected by the positions of $\mathrm{Al}$ and $\mathrm{Mg}$ relative to the tool, and lap joint welding can be modified to double the joint strength. In this study $6061 \mathrm{Al}$ and $\mathrm{AZ31Mg}$, the two most widely used $\mathrm{Al}$ and $\mathrm{Mg}$ alloys were selected.[6]

\section{Objective Of Work}

Samples representing the parameters most likely to cause embrittlement were provided to aluminium alloys. For comparison purposes, samples were also provided which had been welded using parameters that would be most likely to cause good welds. In addition samples were provided of traditional butt welds for comparison. Fractured ductile samples were provided which were welded using worst case parameters for fracture surface study. The main objective of present study on "Experimental investigations and analysis of Friction Stir Welding of aluminium alloys" is to predict tensile strength of friction stir welded 5083 and 2024 aluminium alloy incorporating. Multipleoutputs have been obtained so it create multi objective problem so it will predict the process parameter by TOPSIS method.

\section{Methodology}

The friction stir welded (FSW) Aluminium alloy 5083 is welded with high strength aluminium alloy 2024 T3 welded plate. The flat plates of 5 mm thickness, Aluminium alloy 5083 and 2024 T3 have been cut into the required size $(150 \mathrm{~mm} \times 50 \mathrm{~mm})$ by power hacksaw cutting and milling. The initial joint configuration is obtained by securing the plates in position using mechanical clamps. The direction of welding is normal to the rolling direction. Single pass welding procedure has been used to fabricate the joints. Square butt join has been prepared to fabricate FSW joints. No special treatment was carried out before welding and testing. Non consumable tools made of high speed steel have been used to fabricate the joints. An indigenously designed and developed machine (15 HP; $3000 \mathrm{rpm} ; 25 \mathrm{KN}$ ) has been used to fabricate the joints. The above mentioned geometry of tool pin profile and process parameters have been used to fabricate the joints. The rotational speed best performance level are 400 to $500 \mathrm{rpm}$, welding speed are in between $40-50 \mathrm{~mm} / \mathrm{min}$ and the shoulder diameter are perform in 18-20 $\mathrm{mm}$. So the final parameters are shown in table 1.

Table 1- Process parameter

\begin{tabular}{|c|c|c|c|}
\hline Factor & Level 1 & Level 2 & Level 3 \\
\hline Rotational Speed RPM (RS) & 400 & 450 & 500 \\
\hline Welding Speed mm/min (WS) & 40 & 45 & 50 \\
\hline Shoulder Diameter mm (SD) & 18 & 19 & 20 \\
\hline
\end{tabular}

\section{Strength Test}

Tensile test specimens were machined from both the rolling and transverse directions of the base metal, and in the transverse direction for the weldments. Moreover, an extensometer is used to find the elastic strain during the tensile test. The Charpy impact test, also known as the Charpy V-notch test, is a standardized high strain-rate test which determines the amount of energy absorbed by a material during fracture.

\section{Multi objective Technique}

TOPSIS (technique for order preference by similarity to an ideal solution) method is presented. TOPSIS is a multiple criteria method to identify solutions from a finite set of alternatives. The basic principle is that the chosen alternative should have the shortest distance from the positive ideal solution and the farthest distance from the negativeideal solution. The procedure of TOPSIS can be expressed in a series of steps: 
1. All Experimental Data are converted $\mathrm{S} / \mathrm{N}$ ratio.

2. The Experimental Design Matrix along with normalized response $\left(R_{i j}\right)$ is shown in Table $X . R_{i j}$ is the normalized value and this normalized matrix can be calculated by the equation 1 .

$$
R_{i j}=\frac{x_{i j}}{\sqrt{\sum_{i=1}^{30} x_{i j}^{2}}}
$$

Where $\mathrm{x}_{\mathrm{ij}}$ is the experimental value of the $\mathrm{i}^{\text {th }}$ attribute of the $\mathrm{j}^{\text {th }}$ experimental run.

3. All attributes of normalized matrix (Rij's) are multiplied by S. D. weights. Resultant matrix is called weighted performance matrix which is denoted by $S_{i j}$ (for $i^{\text {th }}$ experimental run and $\mathrm{j}^{\text {th }}$ response).

4. Now positive ideal solution $\left(\mathrm{S}^{+}\right)$and negative ideal solution are expressed by the following equations and their values are provided.

5. After calculating the $S_{\mathrm{ij}}$ matrix, the next step is to find the distance of positive and negative ideal solutions.

Where $d(x, y)$ is the distance between two fuzzy numbers. This distance of two value of $d+$ and $d-$ are calculated. After calculating the distance between the positive and negative ideal solution, the final step is to determine closeness coefficient $\left(\mathrm{CC}_{\mathrm{i}}\right)$, which is calculated by equation 8 . This $\mathrm{CC}_{\mathrm{i}}$ value indicates the closeness of each the experimental value to the ideal solution that is shown in the same table.

$$
C C_{i}=\frac{d_{i}^{-}}{d_{i}^{+}+d_{i}^{-}}
$$

TOPSIS(technique for order preference by similarity to ideal solution) is a simple method which considered that the chosen alternative should have the shortest distance from the ideal solution and the longest distance from the negative ideal solution.[8]

The tensile test has been carried out in Universal Testing Machine (UTM). The specimen is loaded as per the standard. The specimen finally fails after necking and the ultimate tensile strength. Yield stress, and percentage of elongation have been evaluated. The tensile testing of welded joints is shown from figure 2 to figure 3 .

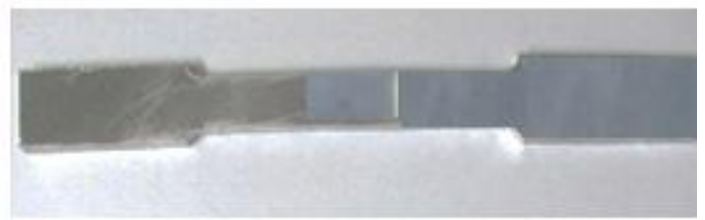

Figure2 Tensile Test Specimen

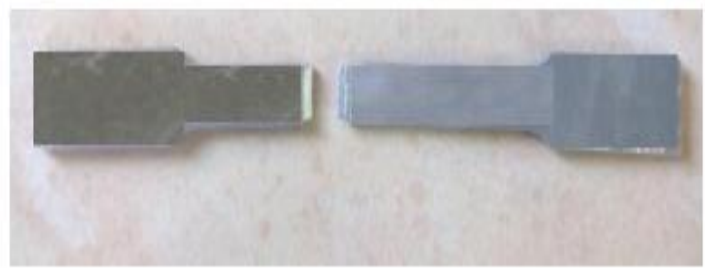

Figure3 Tensile test performed

Tensile strength of the FSW joints were evaluated by conducting test on universal testing machine and Charpy test results is presented in Table2. TOPSIS calculation has shown in table 3.

\begin{tabular}{|c|c|c|c|c|c|}
\hline S No. & $\mathbf{R S}$ & WS & SD & Tensile test (T) N/mm ${ }^{2}$ & Charpy Test (I) MPa \\
\hline 1 & 400 & 40 & 18 & 179 & 53 \\
\hline 2 & 400 & 45 & 19 & 184 & 58 \\
\hline 3 & 400 & 50 & 20 & 186 & 59 \\
\hline 4 & 450 & 40 & 19 & 178 & 63 \\
\hline 5 & 450 & 45 & 20 & 182 & 58 \\
\hline 6 & 450 & 50 & 18 & 186 & 67 \\
\hline 7 & 500 & 40 & 20 & 193 & 62 \\
\hline 8 & 500 & 45 & 18 & 197 & 59 \\
\hline 9 & 500 & 50 & 19 & 189 & 64 \\
\hline
\end{tabular}

Table 2 Response Table 
Table 3TOPSIS Calculation

\begin{tabular}{|c|c|c|c|c|}
\hline $\begin{array}{c}\mathbf{S} / \mathbf{N} \\
\mathbf{T} \\
\end{array}$ & $\begin{array}{c}\mathbf{S} / \mathbf{N} \\
\mathbf{I} \\
\end{array}$ & (T) $\mathbf{R}_{\mathrm{ij}}$ & (I) $\mathbf{R}_{\mathrm{ij}}$ & CCI \\
\hline-45.0571 & -34.4855 & 0.40467 & 0.39256 & 0.0413 \\
\hline-45.2964 & -35.2686 & 0.40682 & 0.40148 & 0.018394 \\
\hline-45.3903 & -35.417 & 0.40766 & 0.40317 & 0.014269 \\
\hline-45.0084 & -35.9868 & 0.40423 & 0.40965 & 0.013818 \\
\hline-45.2014 & -35.2686 & 0.40596 & 0.40148 & 0.019861 \\
\hline-45.3903 & -36.5215 & 0.40766 & 0.41574 & 0.004106 \\
\hline-45.7111 & -35.8478 & 0.41054 & 0.40807 & 0.004672 \\
\hline-45.8893 & -35.417 & 0.41214 & 0.40317 & 0.011573 \\
\hline-45.5292 & -36.1236 & 0.40891 & 0.41121 & 0.003596 \\
\hline
\end{tabular}

\section{Discussions}

During the test a welding speed was used and two specimens for each type of weld and base materials were tested. The testing rig with its principal dimensions is presented as per ASME standard. No root flaws or other defects were detected in all joints. In FSW process heat generated by friction between the surface of the plates and the contact surface of a special tool, composed of two main parts: shoulder and pin. Shoulder is responsible for the generation of heat and for containing the plasticized material in the weld zone, while pin mixes the material of the components to be welded, thus creating a joint. This allows for producing defect-free welds characterized by good mechanical and corrosion properties. The advantages of FSW are due to the fact that the process is carried out with the material to be welded in the solid state. Avoiding melting prevents the production of defects, due, for instance, to the presence of oxygen in the melting bath, and limits the negative effects of material metallurgical transformations and changes strictly connected with changes of phase, the optimize parameter are shown in Fig 4.

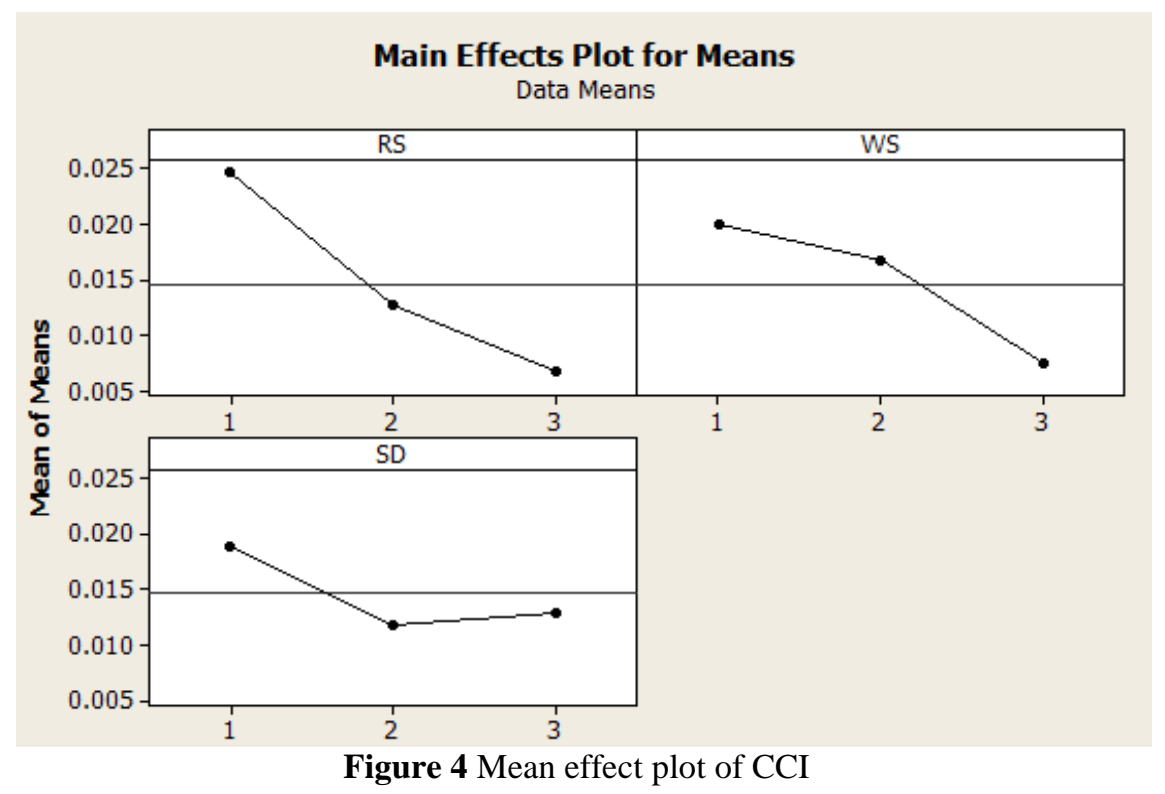

\section{Conclusion}

Aluminium alloy AA5083 and AA2024T3 will be welding by friction stir weld employing different process parameters as obtain by DOE. Their influence on mechanical properties of developed joints will investigate in terms of tensile strength and impact test.By TOPSIS method the optimal setting is obtained is rotation speed $400 \mathrm{rpm}$, welding speed $40 \mathrm{~mm} / \mathrm{min}$ and shoulder diameter is $18 \mathrm{~mm}$ gives the best setting of output

\section{Reference}

[1]. Anastasios D. Kostrivas and John C. Lippold: Simulating Weld Fusion Boundary Microstructures in Aluminium Alloys, Journal of Materials February 2004 pp 65-72.

[2]. Cavaliere P, Nobile R, Panella F W and Squillace A (2006), "Mechanical and microstructural behaviour of 2024-7075 aluminium alloy sheets joined by friction stir welding”, International Journal of Machine Tools \& Manufacture, Vol. 46, pp. 588-594.

[3]. D. M. Rodregues, C. Leitao, R. louro, H. Gouveia, and A. Loureiro, High speed friction stir welding of aluminium alloys, Science and tech. of welding and joining, 15(2010), 676-681.

[4]. Duo Liu, Hiroyuki Nishio and Kazuhiro Nakata (2011), "Anisotropic property of material arrangement in friction stir welding of dissimilar Mg alloys", Materials and Design, Vol. 32, pp. 48184824. 
[5]. Esther T Akinlabi and Stephen A Akinlabi (2012), International Multiconference of Engineers and Computer Scientists, Vol. II.

[6]. Firouzdor V and Kou S (2009), "Al-to-Mg Friction Stir Welding: Effect of Positions of Al and Mg with Respect to the Welding Tool”, Welding Journal, pp. 213s-224s.

[7]. G. Cao and S. Kou, Friction Stir Welding of 2219 Aluminium: Behaviour of $\theta$ (A12Cu) particles. Supplement to the Welding Journal, January 2005.

[8]. Yurdakul, M., \&Cogun, C. (2003). Development of a multi-attribute selection procedure for non-traditional machining processes. Proceedings of the Institution of Mechanical Engineers Part E - Journal of Engineering Manufacture, 217, 993-1009. 